\title{
Guidelines for the use of buprenorphine for opioid use disorder in the perioperative setting
}

Lynn Kohan (D) ,' Sudheer Potru (D , ${ }^{2}$ Antje M Barreveld, ${ }^{3}$ Michael Sprintz, ${ }^{4}$ Olabisi Lane, ${ }^{5}$ Anuj Aryal, ${ }^{6}$ Trent Emerick, ${ }^{7}$ Anna Dopp, ${ }^{8}$ Sophia Chhay, ${ }^{8}$ Eugene Viscusi (id ${ }^{9}$

\section{ABSTRACT}

The boards of directors of the American Society of Regional Anesthesia and Pain Medicine, American Society of Anesthesiologists, American Academy of Pain Medicine, American Society of Addiction Medicine and American Society of Health System Pharmacists approved the creation of a Multisociety Working Group on Opioid Use Disorder (OUD), representing the fields of pain medicine, addiction and pharmacy health sciences. An extensive literature search was performed, and a modified Delphi process was used to assess the literature and expert opinion for each topic, with $100 \%$ consensus being achieved on the statements and each recommendation. The consensus statements were then graded by the committee members using the US Preventive Services Task Force grading of evidence guidelines. Two core topics were identified for the development of recommendations, with both topics achieving 100\% consensus: (1) providing recommendations to aid physicians in the management of patients receiving buprenorphine for medication treatment of OUD in the perioperative setting and (2) providing recommendations to aid physicians in the initiation of buprenorphine in patients with suspected OUD in the perioperative setting. To decrease the risk of OUD recurrence, buprenorphine should not be routinely discontinued in the perioperative setting. Buprenorphine can be initiated in untreated patients with OUD and acute pain in the perioperative setting to decrease the risk of opioid recurrence and death from overdose.

'Divsion of Pain Medicine/Department of Anesthesia, University of Virginia, Charlottesville, Virginia, USA ${ }^{2}$ Department of Anesthesiology/Division of Pain Medicine, Emory University School of Medicine, Atlanta, Georgia, USA

${ }^{3}$ Department of Anesthesiology, Tufts University School of Medicine, Boston, Massachusetts, USA

${ }^{4}$ Division of Geriatrics and Palliative Medicine, The University of Texas Health Science Center at Houston, Houston, Texas, USA

${ }^{5}$ Department of Anesthesiology, Emory University

School of Medicine, Atlanta, Georgia, USA

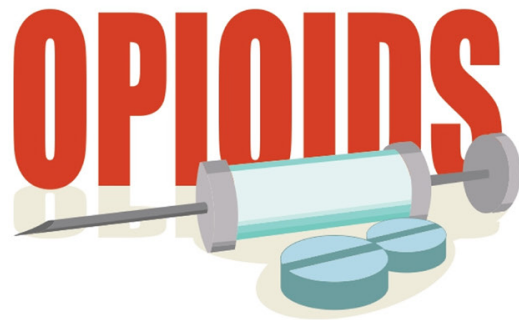

Opioid Use Disorder (OUD)

- Affects 2.5 million people in the U.S.'

- Medication for OUD is effective and saves lives.?

- Treatment gaps exist; there's not enough buprenorphine prescribers. - Death rate is highest for patients with OUD in the first month after hospital discharge."

\section{Opioid Use Disorder Guidelines}

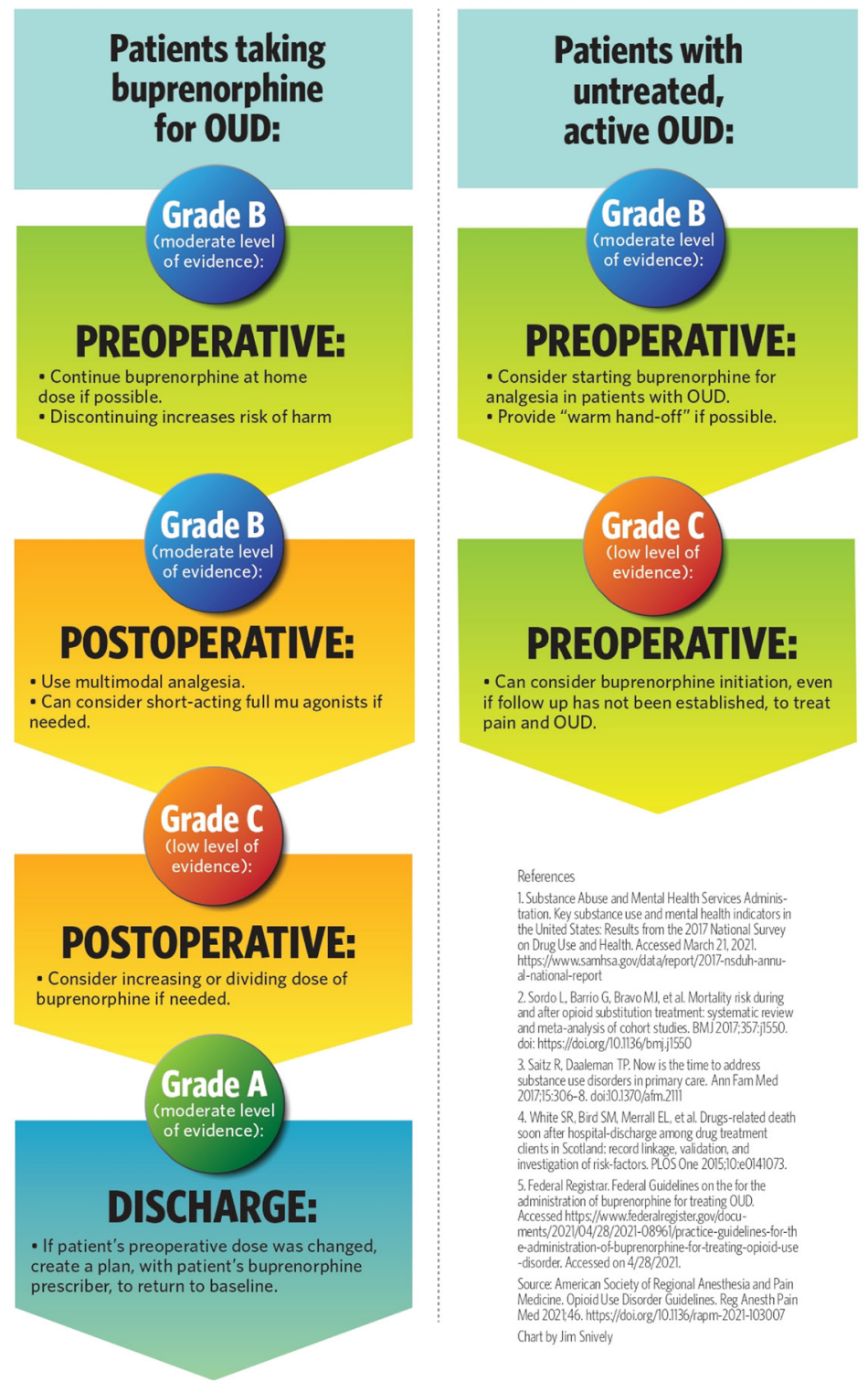


${ }^{6}$ Department of Anesthesiology, VA Tennessee Valley Healthcare System Nashville Campus, Nashville, Tennessee, USA

${ }^{7}$ Department of Anesthesiology, University of Pittsburgh Medical Center, Pittsburgh, Pennsylvania, USA ${ }^{8}$ American Society Health System Pharmacists, Bethesda, Maryland, USA

${ }^{9}$ Department of Anesthesiology, Thomas Jefferson University, Philadelphia, Pennsylvania, USA

Correspondence to Dr Sudheer Potru, Atlanta VA Medical Center, Emory University School of Medicine, Atlanta, Georgia, USA; sudheer.potru@emory.edu

Twitter Lynn Kohan @kohanlynn and Sudheer Potru @SPotruD0

Contributors All authors participated in development of the original manuscript on which this infographic was created. LK authored the infographic.

Funding The authors have not declared a specific grant for this research from any funding agency in the public, commercial or not-for-profit sectors.

Competing interests None declared.

Patient consent for publication Not required.

Provenance and peer review Commissioned; internally peer reviewed.
(C) American Society of Regional Anesthesia \& Pain Medicine 2021. No commercial re-use. See rights and permissions. Published by BMJ.

\section{A Check for updates}

To cite Kohan L, Potru S, Barreveld AM, et al. Reg Anesth Pain Med 2021;46:860-861.

Received 10 August 2021

Accepted 14 August 2021

Published Online First 26 August 2021

\section{Linked}

- http://dx.doi.org/10.1136/rapm-2021-103007

Reg Anesth Pain Med 2021;46:860-861. doi:10.1136/rapm-2021-103092

\section{ORCID iDs}

Lynn Kohan http://orcid.org/0000-0003-0407-806X Sudheer Potru http://orcid.org/0000-0002-70811154

Eugene Viscusi http://orcid.org/0000-0003-02604396

\section{REFERENCES}

1 Substance Abuse and Mental Health Services Administration. Key substance use and mental health indicators in the United States: results from the 2017 national survey on drug use and health. Available: https://www.samhsa.gov/data/report/ 2017-nsduh-annual-national-report [Accessed 21 Mar 2021].

2 Sordo L, Barrio G, Bravo MJ, et al. Mortality risk during and after opioid substitution treatment: systematic review and meta-analysis of cohort studies. BMJ 2017;357:j1550.

3 Saitz R, Daaleman TP. Now is the time to address substance use disorders in primary care. Ann Fam Med 2017;15:306-8.

4 White SR, Bird SM, Merrall ELC, et al. Drugs-related death soon after hospital-discharge among drug treatment clients in Scotland: record linkage, validation, and investigation of risk-factors. PLoS One 2015;10:e0141073.

5 Federal Registrar. Federal guidelines on the for the administration of buprenorphine for treating OUD. Available: https://www.federalregister.gov/documents/ 2021/04/28/2021-08961/practice-guidelines-for-th e-administration-of-buprenorphine-for-treating-opioiduse-disorder [Accessed 28 Apr 2021]. 